\title{
Reseña de Ángeles maraqueros. Trazos neobarroc-s-ch-os en las poéticas la- tinoamericanas, ed. Ángeles Mateo del Pino, Buenos Aires, Katatay, 2013, 464 pp. ISBN: 978-987-29565-0-9
}

\section{Jesús Páez}

Universidad de Las Palmas de Gran Canaria ESPAÑA jpaez@dfe.ulpgc.es

[Hipogrifo, (issn: 2328-1308), 3.1, 2015, pp. 273-275]

Recibido: 29-03-2014 / Aceptado: 02-06-2014

DOI: http://dx.doi.org/10.13035/H.2015.03.01.18

No parece necesario a estas alturas justificar ni dudar de la importancia que la estética barroca tuvo y tiene en Hispanoamérica a quien puede decirse que su literatura debe el mayor porcentaje de su imaginario, que se puede detectar desde las primeras crónicas, persistiendo hasta ese movimiento que ha dado en llamarse neobarroco.

Este es un libro que, al toparse con él, no deja indiferente y es evidente que incita a aproximarse desde su alto título, Ángeles Maraqueros, y también desde la ilustración de portada, donde se conforma el pleno contenido de ese rótulo en un dibujo que combina el «amorcillo» europeo, enraizado en el arte y la cultura de la vieja Europa desde el Renacimiento, en pleno proceso de ejecución de un instrumento arraigado en lo popular; así pues, no es el angelito que toca las trompetas o las campanillas, ni siquiera las populares panderetas. No. Se trata de los divinos e inocentes seres celestes que, más allá del neopopularismo, van tocando un instrumento percusivo y rítmico que se nos antojan provocadores de una revolución celeste. En efecto, los espíritus puros de las alturas tocan las maracas. La imaginación frente a la realidad en América Latina. Y volvemos a estar en lo real maravilloso, en el realismo mágico que, a pesar de inventarlo Europa, se hace carne viva en Hispanoamérica. Y en muchos matices y vertientes. Una, el neobarroco. En esa lúdica portada se anticipan con lenguaje de la imagen los controvertidos términos de barroco, neobarroco, neobarrocho, neobarroso e incluso transbarroco, que van a ser esclarecidos e interpretados en los densos contenidos de cada uno de los artículos que conforman el grueso del volumen. 
La profesora Ángeles Mateo del Pino ha decidido trazar con pulso esta nueva transculturación estética y comienza guiñándonos con el título de su Introducción («Barroco constante más allá de...») y jalonando las partes de su Estudio preliminar con versos del celebérrimo poema de Quevedo, el Barroco - no el Neo- por antonomasia. A más de un lema de Lezama Lima, el Neobarroco por antonomasia.

La autora nos confiesa desde un primer momento sus intenciones: expresar la complejidad (de la ambigüedad a la metamorfosis) del Barroco clásico y el Neobarroco contemporáneo latinoamericano tras los planteamientos muy conocidos de Carpentier y Lezama. Auxiliándose de certeros y documentados conocimientos, de un gran volumen de lecturas y una muy reciente y abundante bibliografía, la profesora Mateo del Pino juega y desvela la actitud neobarroca en la insólita, pero paradójicamente asumible relación entre la inquietante pregunta inicial acerca de la conexión entre elementos tan dispares como el ángel, la medusa, el camaleón y la sirena. Y habrá una interesante respuesta que no queremos desvelar aquí, porque lo interesante es seguir el proceso en el libro.

Los sucesivos análisis sincrónicos y diacrónicos acerca de las definiciones, denominaciones, concepciones, etc. del Barroco, su metamorfosis hispanoamericana donde se asegura y muestra que no sólo Góngora es el sustrato de Lezama y Carpentier, sino el conceptismo quevediano en casi la misma medida, culminan con la aseveración de que el Barroco no ha podido ser aniquilado, a pesar de los años en que floreció en el mundo hispánico.

Muy interesante es la alusión y comentario así como el análisis de las cuatro denominaciones que se derivan del Barroco moderno: se nos sitúan y enumeran aquí los primeros y pioneros vinculados al espacio de Brasil y Cuba, «Neobarroco y otras perlas bruncas», analizando la investigadora los contenidos de los «morceaux choisis», auténtico «corpus» imprescindible del libro que se muestran antologizados en la Segunda Parte. Continúa en la misma tónica para desvelar las denominaciones, componentes, actitudes, obras reveladoras, etc, del espacio rioplatense, «Del neobarroso al neoborroso rioplatense»; con la denominación sorprendente de «Neobarrocho en la loca geografía» incursiona en el espacio chileno para desembocar finalmente en la concepción d'orsiana de «Transbarroco, mise en scène y atrezzo» latinoamericano, analizando experiencias como la performatividad, la espiritualidad marginal, la cocina, el cine y la música.

Como ya hemos subrayado, la Segunda parte de estos Ángeles maraqueros está constituida por casi una veintena de ponencias o microensayos monográficos debidos a muy diversos estudiosos, merecedores cada uno de una reseña explicativa de sus interesantes contenidos: Roberto Echavarren, Mario Cámara, Ismael Gutiérrez, Nanne Timmer, Jorge Chen Sham, Paula Siganevich, Enrique Foffani, Jimena Néspolo, Fernando Moreno, Macarena Areco, Zenaida Suárez, María A. Semilla Durán, Javier Bello, Ángeles Mateo del Pino, Gloria Godínez, Nieves Pascual y José Rodríguez Herrera. Supone esta segunda parte del libro una certera sección y selección que consta de una gavilla de estudios agrupados en torno a cada uno de los términos en dilucidación: así para el de Neobarroco se asignan 5 acercamientos, entre los que encontramos la dialéctica «barroco neobarroco», trazada 
por Roberto Echavarren hasta la pregunta acerca del neobarroquismo de Reinaldo Arenas de José Ismael Gutiérrez . En número de cuatro aparecen las disquisiciones acerca del neobarroco entre los que destacamos el estudio acerca de los cambios, derivas y transformaciones del neobarroco rioplatense con autoría de Paula Siganevich; 4 estudios dedicados esta vez al Neobarrocho pueden leerse bajo el título de «Neobarrocho en la loca geografía» del que destacamos por su claridad el titulado «Los límites del barroco: Pedro Lemebel y la insurrección estética»; en último lugar de esta sección, de nuevo 4 autores son los que se ocupan del Transbarroco, de entre los cuales merece atención el que lleva a cabo José Rguez. Herrera que importa el término a nuestro país cuando investiga «el carnaval neobarroco en las películas de Pedro Almodóvar»

En definitiva, libro crucial para entender este insólito, aunque arraigado en lo sólito, fenómeno que es el Neobarroco en Latinoamérica, capaz de encontrar la originalidad autóctona desde su «imaginación colonizada», al decir de Carlos Fuentes y seguir enriqueciendo el espacio con las «letras del continente mestizo», al decir de Mario Benedetti.

Repetimos: imprescindible y de obligada lectura para especialistas en Literatura. 
